\title{
Effect of Soaking Coffee (Coffea arabica) Cherries on Biochemical Composition and Cup Quality of Coffee Brew
}

\author{
Pauline Wairimu Ikumi ${ }^{1}$, Richard Kipkorir Koskei ${ }^{2}$, Daniel Mwangi Njoroge ${ }^{3}$, \\ Cecilia Wagikondi Kathurima ${ }^{4}$ \\ 1, 2, 3 (Institute of Food Bioresources, Dedan Kimathi University of Technology, Kenya) \\ ${ }^{4}$ (Coffee Research Institute, Kenya Agricultural and Livestock Research Organization, Kenya)
}

\begin{abstract}
During the peak harvest season, most coffee processing factories may lack sufficient capacity to process coffee cherries. Such processing delays lead to undesirable fermentation affecting the quality of the coffee. Soaking of coffee cherries may be adopted in an attempt to preserve the cherries but information on the effects of this practice on chemical composition and sensory quality of coffee is limited. This study aimed at determining the biochemical composition and cup quality of soaked coffee cherries, for a period of seven and ten days with daily change of soaking water and without change of soaking water with the control being freshly processed coffee cherries. The levels of caffeine, chlorogenic acids, sugars and trigonelline were determined by HPLC methods. The cup quality was determined by the use of 3 trained coffee cuppers. The results of this study showed that soaking of coffee cherries did not have significant variations in the level of trigonelline, chlorogenic acids, caffeine and sucrose. The levels of trigonelline ranged between 0.88-1.15\%, chlorogenic acid $6.71-8.13 \%$, caffeine 1.04-1.13\% and finally sucrose 5.67-6.60\%. The results of sensory analysis revealed significant variations $(p \leq 0.05)$ in terms of raw bean color, flavor and class of the coffee brew. In terms of quality, coffee samples obtained from freshly processed coffee cherries scored the highest at 4.78 (fair to good quality). Discrimination function analysis placed the freshly processed coffee cherries further distinctively from other treatments thus yielding the best quality.
\end{abstract}

Key Words: Chemical composition, coffee cherries, cup quality, soaking.

\section{Introduction}

Coffee belongs to the genus Coffea in the Rubiaceae family and is cultivated throughout the world as one of the most popular beverages[1]. It is composed of both volatile and non-volatile components which include alcohols, caffeine, trigonelline and sugars among others. According to [2], sucrose is one of the main sugars in the coffee beans at 5\% to 9.5\% in Coffea arabica and 4\% to 7\% in Coffea canephora. Robusta coffee has a higher caffeine content of about $2.2 \%$, while Arabica coffee has about $1.2 \%$ with a range of 0.6 to $1.9 \%$ [3]. Coffee quality is defined in terms of organoleptic cup-quality, physical appearances and inherent chemical constituents of the green coffee bean [4]. Soaking of coffee cherries is usually done as a method of sorting so as to; remove leaves, unripe cherries, stones and other impurities as well as to stop dry fermentation which can contribute to the undesirable bitter taste of coffee [5]. The practice of soaking coffee cherries prior to pulping also helps in softening the outer skin and underlying pulp making pulping easier. In addition, soaking of coffee cherries can be used to slow down the rate of fermentation [6] of coffee cherry during the peak season where there is a lot of cherry but limited capacities by factories to process them immediately. Soaking of coffee parchment has been previously practiced and has been shown to improve the flavor profile of coffee [7]. However, there is limited information on the effect of soaking coffee cherries on biochemical composition and cup quality of coffee. This study aimed at determining the biochemical composition and cup quality of soaked coffee cherries of Ruiru 11 cultivar, for a period of seven and ten days with daily change of soaking water and without change of soaking water for the entire soaking period with the control being freshly processed coffee cherries.

\subsection{Sampling and treatments}

\section{Materials And Methods}

The ripe coffee cherries of Ruiru 11 obtained from Dedan Kimathi University farm $\left(0^{\circ} 23^{\prime} 43.4^{\prime \prime} \mathrm{S}\right.$ $\left.36^{\circ} 57^{\prime} 50.2^{\prime \prime} \mathrm{E}\right)$ were classified into two treatments which were used in the preparation of the coffee samples. For the first treatment, the cherries were soaked under water in a bucket at room temperature $\left(26 \pm 0.13^{\circ} \mathrm{C}\right)$ with 3 replicates each weighing $15 \mathrm{kgs}$. On the $7^{\text {th }}$ day and $10^{\text {th }}$ day, $7.5 \mathrm{kgs}$ of the cherries were sampled, pulped, fermented for 48 hours, washed and sun dried. The second treatment consisted of soaking coffee cherries in water without change of the soaking water for the entire soaking period and was done in 3 replicates each weighing $15 \mathrm{kgs}$. On the $7^{\text {th }}$ and $10^{\text {th }}$ day of soaking, samples each weighing $7.5 \mathrm{kgs}$ were taken, pulped using a 
mechanical pulper, fermented for 48 hours, washed and dried in the sun to obtain a moisture content of $8-12 \%$. The treatments were carried out in a completely randomized design (CRD) with three replicates.

\subsection{Methods}

\subsubsection{Caffeine content determination}

Caffeine content was determined as described by [3] with minor modifications. Five grams of the ground green coffee powder were weighed in a $250 \mathrm{~mL}$ Erlenmeyer flask then $3.5 \mathrm{~g}$ of magnesium oxide and $200 \mathrm{~mL}$ of double distilled water added. The mixture was refluxed by boiling for 25 minutes and then allowing it to cool. This mixture was then strained under vacuum on celite and the recovery of the filtrate done in a 250 $\mathrm{mL}$ flask which was adjusted to volume with distilled water. Twenty $\mathrm{mL}$ of this solution was pipetted into 100 $\mathrm{mL}$ flask adjusting to volume with $15 \%$ acetonitrile, $0.1 \%$ formic acid and $85 \%$ distilled water mobile phase. The extracts obtained were filtered using millex $(0.45 \mu \mathrm{m})$ filters and injected into Knauer HPLC (Japan) which was fitted with a $\mathrm{C} 18$ and $250 \times 4.6 \mathrm{~mm}$ column, flow rate $1 \mathrm{~mL} / \mathrm{min}$, pulse diode array detector set at $278 \mathrm{~nm}$, and sample volume $20 \mu \mathrm{l}$.

\subsubsection{Chlorogenic acid determination}

Chlorogenic acids content was determined as described by [8]. Two grams of ground green coffee sample was precisely weighed in $250 \mathrm{~mL}$ beakers and $100 \mathrm{~mL}$ of distilled water added to each of the samples. The mixture obtained was then boiled for 5 minutes while continuously stirring. The boiled samples were allowed to cool for 30 minutes and the solution filtered with a $0.45 \mu \mathrm{m}$ filter paper. The chlorogenic acid extract was then injected into Knauer HPLC (Japan) which was fitted with a C18 and $250 \times 4.6$ mm column, flow rate 1 $\mathrm{mL} / \mathrm{min}$, pulse diode array detector set at $278 \mathrm{~nm}$, and sample volume $20 \mu \mathrm{l}$.

\subsubsection{Determination of trigonelline content}

The trigonelline content of the green coffee beans was analyzed using the method described by [9] with minor modifications. To extract trigonelline, the green coffee powder was mixed with methanol in the ratio of 1:9 (v/v). This mixture was vortexed for $60 \mathrm{~s}$ and kept on rotary shaker at $10 \mathrm{rpm}$ for a period of 12 hours. The resultant mixture was then centrifuged at $3000 \mathrm{rpm}$ for 10 minutes and the upper layer separated and injected into the HPLC.

\subsubsection{Determination of sucrose content}

The sucrose content was determined using HPLC analysis as described by [10] with slight modifications. One gram of the sample was added into a flask containing $50 \mathrm{~mL} 95 \%$ ethanol. The mixture was refluxed for one hour and cooled followed by filtration using a Whatman filter paper no.42. The filtrate obtained was evaporated to dryness using rotor vapors. This was then reconstituted with a $10 \mathrm{~mL}$ mobile phase that contained acetonitrile and water in the ratio of 75 to 25 and filtered using $0.45 \mu \mathrm{m}$ filter paper. A sample of $20 \mu 1$ was injected into Knauer HPLC ( Japan) fitted with refractive index detector, Knauer XG166 column, $250 \times 46 \mathrm{~mm}$, Eurosphere $100-5 \mathrm{NH}_{2}$ packing at a flow rate of $1 \mathrm{~mL} / \mathrm{min}$.

\subsection{Sensory evaluation}

Sensory evaluation was done according to [11] as described by [12] with minor modifications. The parameters evaluated included the raw bean color, acidity, flavor, body and overall class of the liquor by 3 trained coffee cuppers on a scale of 0 to 7 . According to (13) flavor refers to a combination of gustatory (sense of taste), olfactory (sense of smell), and trigeminal (chemesthesis) sensations observed during tasting. In addition, [13] describes acidity as the basic taste produced by dilute aqueous solution of most acidic substance. During coffee tasting, body refers to the heaviness that the coffee brew exerts on the mouth of the taster. All the sensory parameters (color, acidity, flavor and body) assessed constituted a final sensory score (class) which is an indication of the broad quality performance of a particular coffee.

\subsection{Data analysis}

Biochemical composition data obtained was analyzed using Statistical Package for Social Scientist (SPSS) software Version 20 where variability among the different samples was done using ANOVA. The differences between means were separated using Duncan multiple range Test. Significant differences between means were established at $\mathrm{p} \leq 0.05$. Sensory analysis data was subjected to analysis of variance and multivariate analysis. Mean seperation was done using Student-Newman-Keuls $\left(\mathrm{SNK}_{5 \%}\right)$ test by Costat. Discriminant Function analysis was done using XL-STAT. 


\subsection{Biochemical composition}

\section{Results And Discussion}

Chlorogenic acids are known to contribute to astringency, bitterness, and acidity of the coffee brew [14]. In this study, the levels of chlorogenic acids ranged between $6.71 \pm 0.69$ to $8.13 \pm 0.82 \%$ which were within the range reported in literature. Report by [15] indicated the range of $4-8.4 \%$ of chlorogenic acid in Arabica coffee. With regards to chlorogenic acids, no significant differences $(p \leq 0.05)$ were observed between the coffee samples soaked for 7 and 10 days with daily change of water and those soaked without change of water for the entire soaking period and the freshly processed coffee cherries. The report of [16] showed that the level of chlorogenic acids in dry matter vary between $3.5 \%$ and $7.5 \%$. The caffeine content for the soaked coffee cherries and freshly processed coffee cherries was in the range of $1.04 \pm 0.4$ to $1.13 \pm 0.61 \%$. There were no significant differences $(\mathrm{p} \leq 0.05)$ between the treatments used compared to the freshly processed coffee cherries in terms of caffeine content as observed in this study. These findings were in agreement with those of [17] who reported that the range of caffeine content in green Arabica coffee beans is between 0.6 to $1.9 \%$ with the average being $1.2 \%$. According to [18], caffeine is bitter in taste and plays a minimal role in contributing to a bitter tinge in the coffee beverage. The levels of trigonelline obtained in this study ranged from $0.88 \pm 0.27$ to $1.15 \pm 0.20 \%$ (TABLE 1). From the study; it was noted that, there were no significant differences $(\mathrm{p} \leq 0.05)$ between the soaked cherries and the freshly processed cherries in relation to the level of trigonelline content. The findings of this study agree with those of [2] on the trigonelline content who reported a range of $0.88 \%$ $1.77 \%$ in Arabica coffee. Trigonelline is a pyridine derivative known to contribute indirectly to the formation of appreciated flavor products including furans, pyrazine, alkyl-pyridines and pyrroles during coffee roasting [2] . Sucrose is of importance to coffee flavor and quality and accounts for up to $9 \%$ of Coffea arabica dry weight and just about half of it in Coffea canephora [14]. From the study, the sucrose content ranged from $5.67 \pm 0.31$ to $6.60 \pm 1.31 \%$. The results indicated that there was no significant difference $(p \leq 0.05)$ on the sucrose content of the green coffee beans between the treatments. The findings on the sucrose content in the study, agrees with the report of [2] who indicated that for Arabica coffee the percentage sucrose level is in the range of 5.1-9.4\%. In addition, [10] reported the sucrose level for Arabica coffee to have a range of 5\%-8.5

Table 1: Biochemical composition of green coffee beans obtained from soaked coffee cherries.

\begin{tabular}{|l|l|l|l|l|}
\hline Treatment & Chlorogenic acid g/100g & Caffeine g/100g & Trigonelline g/100g & Sucrose g/100g \\
\hline 7 days soaking with daily change of water & $7.11 \pm 0.86^{\mathrm{a}}$ & $1.08 \pm 0.97^{\mathrm{a}}$ & $0.97 \pm 0.84^{\mathrm{a}}$ & $5.67 \pm 0.31^{\mathrm{a}}$ \\
\hline 10 days soaking with daily change of water & $8.13 \pm 0.82^{\mathrm{a}}$ & $1.13 \pm 0.61^{\mathrm{a}}$ & $0.97 \pm 0.85^{\mathrm{a}}$ & $6.60 \pm 1.31^{\mathrm{a}}$ \\
\hline 7 days soaking without change of water & $6.71 \pm 0.69^{\mathrm{a}}$ & $1.09 \pm 0.60^{\mathrm{a}}$ & $0.97 \pm 0.55^{\mathrm{a}}$ & $6.32 \pm 1.52^{\mathrm{a}}$ \\
\hline 10 days soaking without change of water & $7.26 \pm 0.11^{\mathrm{a}}$ & $1.04 \pm 0.40^{\mathrm{a}}$ & $1.15 \pm 0.42^{\mathrm{a}}$ & $6.29 \pm 0.27^{\mathrm{a}}$ \\
\hline Freshly processed coffee cherries (Control) & $7.57 \pm 1.07^{\mathrm{a}}$ & $1.10 \pm 0.24^{\mathrm{a}}$ & $0.88 \pm 0.27^{\mathrm{a}}$ & $6.39 \pm 0.54^{\mathrm{a}}$ \\
\hline
\end{tabular}

Mean values followed by the same letter(s) in a column are not significantly different from each other at $\mathrm{p} \leq$ 0.05 .

\subsection{Sensory analysis}

\subsubsection{Effect of different soaking methods of coffee cherries on sensory quality of coffee}

During sensory analysis, the raw bean color, flavor and class of the coffee brew were assessed which are important parameters used in marketing of coffee as they contribute to cup quality. The results for the sensory analysis are presented in Table 2. In sensory analysis, the raw bean color, body and flavor parameters were assessed using the following points: 1-greyish blue, 2-greyish green with blue tinge, 3-greyish green, 4greyish green with brown tinge, brownish grey green, 6-greenish and 7- brownish for raw bean color analysis. For the liquor, the acidity was assessed based on the points as follows; 1-pointed, 2-medium, 3-light medium, 4light and 5-lacking acidity. In terms of the body of the liquor, 1-full, 2- medium, 3- light medium, 4-light and 5lacking. Finally the flavor was assessed based on the scale as follows: 1-fine, 2-good to fine, 3-good, 4- fair to good, 5- Fair average quality (FAQ), 6-poor to fair and 7-poor [11]. Analysis of variance performed on the sensory data displayed significant differences $(p \leq 0.05)$ among the treatments with freshly processed coffee cherries showing significant differences in raw bean colour. The freshly processed coffee cherries scored 2.67 (greyish green with blue tinge) being the best while the coffee sample soaked in water for 10 days without change of water had 4.44 (greyish green with brown tinge) which was the lowest. The difference in color between the green coffee beans from the freshly processed coffee cherries and soaked coffee cherries could be attributed to the effect of soaking. This is in agreement with the report of [7] who indicated that soaking of coffee cherries affects color. This could be attributed to the effect of leaching of color pigments from the seed coat pigment of the coffee cherry. In terms of flavor and overall class of the coffee brew, the freshly processed coffee cherries scored the best at 4.78 and $4+$ repectively while the sample soaked in water for 10 days without change of water scored poorest at 5.33 and an overall class of 5. In this study, the score of flavor and class of the coffee brew were significantly different $(\mathrm{p} \leq 0.05)$ between the samples from the freshly processed coffee 
cherries and those obtained from soaked cherries for 7 and 10 days with and without change of water (TABLE 2 ). The flavor of coffee is a combined impression of all gustatory sensations and retro-nasal aromas that go from the mouth to the nose when coffee brew is slurped into the mouth [19]. The samples from the freshly processed coffee cherries scored the highest at 4.78 (fair to good) while that from coffee cherries soaked for 10 days without change of water scored 5.3 (FAQ). There were no significant differences $(\mathrm{p} \leq 0.05)$ observed with regards to the body and acidity of the brew between the soaked coffee cherries and the freshly processed coffee cherries (TABLE 2). When acidity is bright, it is favorable or desirable but when sour the acidity is unfavorable. It contributes to the liveliness and sweetness of coffee when it is first slurped into the mouth for good quality coffee but if overly intense and dominating it may be unpleasant [19].

Table 2: Mean sensory variables of raw bean color and coffee brew of coffee subjected to different soaking treatments

\begin{tabular}{|l|l|l|r|l|l|}
\hline Treatments & Raw bean color & Body & \multicolumn{1}{|l|}{ Acidity } & Flavor & Class \\
\hline Freshly processed cherry (Control) & $2.67^{\mathrm{a}}$ & $2.11^{\mathrm{a}}$ & $2.11^{\mathrm{a}}$ & $4.78^{\mathrm{a}}$ & $4+^{\mathrm{a}}$ \\
\hline Soaked with daily change of water $\left(7^{\text {th }}\right.$ day) & $3.33^{\mathrm{b}}$ & $2.22^{\mathrm{a}}$ & $2.33^{\mathrm{a}}$ & $5.00^{\mathrm{ab}}$ & $4^{\mathrm{ab}}$ \\
\hline Soaked with daily change of water $\left(10^{\text {th }}\right.$ day) & $3.78^{\mathrm{bc}}$ & $2.22^{\mathrm{a}}$ & $2.33^{\mathrm{a}}$ & $5.00^{\mathrm{ab}}$ & $4^{\text {ab }}$ \\
\hline Soaked with no change of water $\left(7^{\text {th }}\right.$ day) & $4.00^{\mathrm{bc}}$ & $2.33^{\mathrm{a}}$ & $2.56^{\mathrm{a}}$ & $5.22^{\mathrm{ab}}$ & $4^{\mathrm{ab}}$ \\
\hline Soaked with no change of water $\left(10^{\text {th }}\right.$ day) & $4.44^{\mathrm{c}}$ & $2.33^{\mathrm{a}}$ & $2.78^{\mathrm{a}}$ & $5.33^{\mathrm{b}}$ & $5^{\mathrm{c}}$ \\
\hline
\end{tabular}

Means in a column with a different letters are significantly different $(p \leq 0.05)$. Means separated by StudentNewman-Keuls (SNK5\%) test

\subsubsection{Discriminant function analysis of the sensory variables of soaked coffee cherries}

Discrimination function analysis defines the variables which discriminate between two or more naturally occurring groups and whether these groups contrast with regard to the mean of a variable to predict group membership. The sensory data generated from coffees exposed to different soaking treatments was subjected to discriminant function analysis (DFA). In this study, discriminant function analysis revealed the variables (raw bean color, flavor and class) that contributed significantly to the discrimination. Discriminant function analysis showed that the first discriminant factors which included; raw bean color, flavor and class of the brew, explained $97.32 \%$ total variation. Hence their contribution was much greater to the discrimination (Fig 1). Using sensory variables the freshly processed coffee samples portrayed the best quality and was placed further distinctively from the other treatments (Fig 1). The factors which contributed significantly $(\mathrm{p} \leq 0.05)$ to the discrimination were raw bean color (9.3), flavor (3.304) and class (6.2) (Table 3) while acidity (0.867) and body $(0.389)$ showed the least contribution to the discrimination.

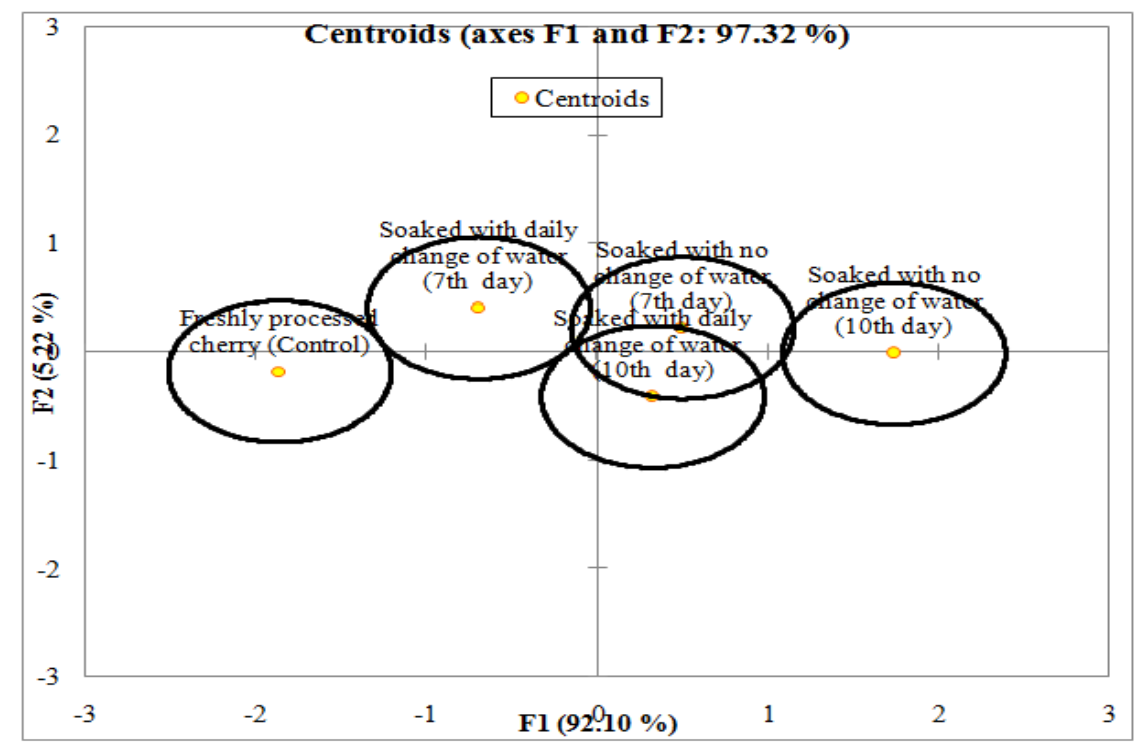

Fig 1: Discriminant factor analysis (DFA) based on sensory data of coffee under different soaking treatments.

Table 3: Contribution of the specific quality variables to the discrimination

\begin{tabular}{|c|c|c|c|c|c|}
\hline Variable & Lambda & $\mathrm{F}$ & DF1 & DF2 & p-value \\
\hline Raw bean color & 0.518 & 9.300 & 4 & 40 & $<0.0001$ \\
\hline Acidity & 0.920 & 0.867 & 4 & 40 & 0.492 \\
\hline Body & 0.963 & 0.389 & 4 & 40 & 0.815 \\
\hline Flavor & 0.752 & 3.304 & 4 & 40 & 0.020 \\
\hline Class & 0.617 & 6.200 & 4 & 40 & 0.001 \\
\hline
\end{tabular}

DOI: $10.9790 / 2402-1106021418$

www.iosrjournals.org

17 | Page 


\section{Conclusion}

In conclusion, the soaking of coffee cherries did not have significant effect on the level of biochemical components such as chlorogenic acids, trigonelline, caffeine and sucrose. However, soaking of coffee cherries showed significant effects on the sensory attributes of the raw coffee beans such as color and the flavor and class of the coffee brew. The soaked samples were more discriminated from the fresh samples in terms of raw bean color, flavor and class of the brew and the fresh samples gave better quality than the soaked samples. Due to the development of poor quality attributes such as off flavors in soaked coffee, the coffee cherries should not be subjected to soaking prior to wet processing, but should be processed immediately after harvesting.

\section{Recommendation}

Although the soaking of coffee cherries did not have a significant effect on the biochemical composition of green coffee beans; it negatively affected the sensory quality with regard to the raw bean color, flavor and class of the coffee brew which are important parameters used in marketing and sale of coffee. Therefore, coffee processors and coffee farmers should be discouraged from soaking coffee cherries and emphasis put on improving capacity in coffee processing factories and efficiency of the coffee processing machines.

\section{Acknowledgement}

We wish to express our sincere appreciation to Dedan Kimathi University for the financial support to undertake this work and also to the staff of Coffee Research Institute for the technical support and expertise during laboratory analysis.

\section{References}

[1]. K. Lee, and T. Shibamoto, Analysis of volatile components isolated from Hawaiian green coffee beans ( Coffea arabica L), Flavor and Fragrance journal 17, (2002), 349-351.

[2]. C. Ky, S. Doulbeau, B. Guyo, A. Charrier, J. Hamon, S. Louarn, and M. Noirot, Inheritance of sucrose content in the interspecific cross: Coffea pseudozanguebariae Coffea liberica "dewevrei." Journal of Plant Breeding, 119, (2001)165-168.

[3]. B. M. Gichimu, E. K. Gichuru, G. E. Mamati, and A.B. Nyende, Biochemical Composition Within Coffea arabica cv . Ruiru 11 and Its Relationship With Cup Quality,African Journal of Research 3(3), (2014)31-44.

[4]. A. Sualeh, S. Endris, and A. Mohammed,. Processing Method, Variety and Roasting Effect on Cup Quality of Arabica Coffee (Coffea arabica L .), Discourse Journal of Agriculture and Food Sciences 2(2), (2014) 70-75.

[5]. V. Singh, Wet milling, a 100\% organic kona coffee. (2015). at <www.peleplantations.com/wet-milling-100-organic-kona-coffee/> Web accessed May 2016

[6]. L.P. Mureithi, Working Paper Coffee in Kenya: Some challenges for decent work to stimulate discussion and obtain comments International Labour Office. (2008).

[7]. D. Nugroho, Mutu Fisik dan Citarasa Kopi Arabika yang Disimpan Buahnya Sebelum di- Pulping Physical and Flavor Profiles of Arabica Coffee as Affected by Cherry Storage Before Pulping.Plant physiology 30, (2014), 137-158.

[8]. H. N. Wanyika, E. G. Gatebe, L .M. Gitu, E. K. Ngumba, and C. W. Maritim, Determination of caffeine content of tea and instant coffee brands found in the Kenyan market. African Journal of Food Science 4, (2010) 353-358.

[9]. S. Shailajan, S. Menon, A. Singh, M. Mhatre, and N. Sayed, A validated RP-HPLC method for quantitation of trigonelline from herbal formulations containing Trigonella foenum-graecum (L.) seeds, Journal of Pharmaceutical Methods 2, (2011) 157-160.

[10]. S. Knopp, G. Bytoff, and D. Selmar, Influence of processing on the content of sugars in green Arabica coffee beans, Journal of European Food Research and Technology. 223, (2006) 195-201.

[11]. C. Devonshire, Explanation of the Coffee Report Form. Coffee Board of Kenya Monthly Bulletin. July (1956) 186-187.

[12]. G. Moreno, E. Moreno, and G. Cadena, Bean characteristics and cup quality of the Colombian variety (Coffea arabica) as judged by international tasting panels. in 16th Int. Sci. Colloq. Coffee (1995) 574-583.

[13]. ISO. Sensory analysis - Vocabulary, Second edition, published in Switzerland. (2008). <https://www.nen.nl/pdfpreview/preview_161474.pdf.> Web accessed January 2017.

[14]. A. Farah, Coffee constituents. In J. W. and Sons (Ed.), Chu Y-F. Coffee: Emerging health effects and disease prevention (1st ed.,) (Inc. Blackwell Publishing Ltd. New york, 2012) 21-59.

[15]. A. Farah, M. Monteiro, C. Donangelo, and S. Lafay, Chlorogenic Acids from Green Coffee Extract are Highly Bioavailable in Humans, Journal of Nutrition, 138(12) (2008),2309-2315.

[16]. Y. Narita, and K. Inouye, Inhibitory effects of chlorogenic acids from green coffee beans and cinnamate derivatives on the activity of porcine pancreas, Food Chemistry, 127(4), (2011), 1532-1539.

[17]. A. Belay, Some biochemical compounds in coffee beans and methods developed for their analysis, International Journal of Physical Sciences 6(28), (2011) 6373-6378.

[18]. S. Oestreich-Janzen.. Chemistry of coffee. Elsevier Ltd. (2010) www.documbase.com/Chemistry-of-Coffee-oestreich-janzen.pdf. Web accessed June 2016

[19]. SCAA, SCAAprotocals-cuppingspecialtycoffee. (2015) www.scaa.org/?page=resources\&d=cupping-protocols. Web accessed July 2016 